\title{
Comparative study of Ventilatory Functions of Cotton Mill Workers, Mumbai, India
}

\author{
Ingle A.S $S^{1}$ Venkatraman $B^{2}$, Bagale $K^{3}$, Choudhary $R^{4}$ \\ ${ }^{1}$ Dr Avinash S Ingle, Associate Professor, Department of Physiology, AIIMS-Raipur, RAIPUR, CG, ${ }^{2}$ Dr Brinda \\ Venkatraman, Professor, Department of Physiology, Hinduhrudaysamrat Balasaheb Thackeray Medical College and \\ Dr R. N. Cooper Hospital, Mumbai, ${ }^{3}$ Dr Kiran Bagale, Assistant Professor, Department of Biochemistry, Pt J. N. M. \\ Memorial Medical College, Raipur, CG, ${ }^{4}$ Dr Rajeev Choudhary, Professor, School of studies in Physical Education, \\ Pt. Ravishankar Shukla University, Raipur, CG, India.
}

Address for Correspondence: Dr. Avinash S Ingle, Department of Physiology, AIIMS, RAIPUR, CG, India. Email: dravinashingle2@gmail.com

\begin{abstract}
Background \& objectives: The present observational study was carried out in cotton mill workers of Mumbai to compare the pulmonary functions with those of apparently healthy population and to find out the effect of duration of exposure to the working environment. Materials \& Methods: The study group comprised of 150 cotton mill workers and 150 workers of hospital staff, all males, in age group of 25-60 years. Socio-demographic characteristics and occupational history was noted in predesigned questionnaire performa for both groups. Respiratory functions namely FEV1, FVC, FEV1/FVC \& PEFR were recorded by using portable and electronic instrument pneumotachometer, results were analysed by using difference of means. Results: The pulmonary functions were found to be significantly lower in cotton mill workers as compared to hospital staff and pulmonary functions were correlated negatively with duration of exposure to the cotton dust. Conclusion: In spite of modernization and recent technical evolution the working conditions and occupational environment has still a long way to go as per as the safety of cotton mill workers of Mumbai city is concerned.
\end{abstract}

Key words: Cotton mill workers, Spirometry, Ventilatory functions

\section{Introduction}

At the time of industrial evolution, then rulers (Britishers) gave priority to set up cotton industries at Mumbai, India so in the earlier periods of last century nearly $1 / 3^{\text {rd }}$ of the working population was employed in textile industries [1]. Many studies abroad noticed the high prevalence of cotton related respiratory diseases in cotton mill workers (CMW) although the reported incidence in India was found to be very low as compared to other countries $[2,3]$. In current era cotton industries in India, particularly Mumbai are going through difficult phase with most of them being closed down. Those which are still running, are grossly neglected and the workers continue to work on same old machines thereby increasing the risk of developing the

Manuscript received $10^{\text {th }}$ September 2016

Reviewed: $24^{\text {th }}$ September 2016

Author Corrected: $6^{\text {th }}$ October 2016

Accepted for Publication $18^{\text {th }}$ October 2016 diseases due to inhalation of cotton dust of working environment affecting pulmonary functions [4].

This study was undertaken to know the current status of the pulmonary functions of the workers in textile industries of Mumbai and to compare those with the unexposed population of Mumbai and also to correlate the effect of duration of chronic exposure with lung functions.

\section{Materials and Methods}

The present cross-sectional study was conducted in five cotton mills in Mumbai with prior permission of safety managers of respective cotton mills. A predesigned semi-structured performa and plan was submitted to the ethical committee and same was used as study tool. A study group of 150 cotton mill workers and control 
group of 150 workers from hospital staff who were not directly exposed to cotton dust were randomly selected for the study.

The subjects for the study group were chosen from the departments where exposure to cotton dust is more (i.e. blow room, card room and spinning) whereas the subjects for the Comparison were selected from the Employees State Insurance Scheme hospital of same region of Mumbai city.

The employees who were working at least since seven consecutive years and whose age group is between 25 to 60 years were included in the study whereas the workers with history of smoking, chest and spine related musculoskeletal abnormalities, present or past history of tuberculosis or any active pulmonary infection were excluded from the study.

The permission from hospital and cotton mill management and also the informed consent was obtained from study subjects of both groups before data collection.

Lung function testing- The extent of the lung damage was assessed by measuring lung volumes and capacities with the help of computer attached spirometer that is pneumotachometer. The procedure of Spirometry was performed during the working hours at the daytime and was included parameters like Forced Expiratory Volume during first second (FEV1), Forced Vital Capacity (FVC), Ratio of Forced Expiratory Volume during first second with Forced Vital Capacity (FEV1/ FVC) and Peak Expiratory Flow Rate (PEFR). The pneumotachometer was calibrated biologically every day by using standard procedure [5]. The details including the medical history, occupational history and personal information was noted down.

The subjects were allowed to relax for $10 \mathrm{~min}$ to become mentally and physically stable prior to the testing. The procedure (as outlined below) was explained to the subjects in detailed manner. During the procedure each subject was seated comfortably in a straight posture with the neck extended. Study subjects were then instructed to perform the manoeuvre as per the standard American Thoracic Society (ATS) guidelines [7].

The results were noted directly from the screen of the Pneumotachometer and were corrected to Body Temperature Atmospheric pressure and Air Saturated with water vapours (BTPS). At least three attempts of reasonably good efforts were made. The best test i.e. the test which gave the largest sum of FEV1 and FVC was selected [6].

The predicted values were calculated for each parameter considering the age and height with the help of chart provided with the instrument [7]. Then data was corrected for Indian standards $[8,9]$.

The instrument used to study the pulmonary function was "Micro-plus" by Micro Medical Ltd. Rochester, Kent, England. It is an electronic type of Pneumotachometer which is handy, portable, fulfils the performance criteria. The data were entered in Microsoft-Excel Sheet and Analysed by using Statistical Software "SPSS". Test of significance was T test and the correlation between duration of exposure and pulmonary function parameters was determined by using Pierson correlation method.

\section{Results}

The difference seen in the study group and control group among age, height and weight was not statistically significant (table-1) eliminating the effect of these factors on pulmonary functions.

Table-1: Demographics of the population studied.

\begin{tabular}{|c|c|c|c|c|}
\hline Groups & Age (Years) & Height $(\mathbf{C m s )}$ & Weight $(\mathbf{K g s})$ & Years of Exposure \\
\hline Cotton Mill Workers & $44.33+8.31$ & $163.43+5.84$ & $57.42+8.60$ & $22.34 \pm 7.80$ \\
\hline Comparison Group & $45.10 \pm 10.04$ & $164.76 \pm 5.99$ & $62.84 \pm 6.93$ & $22.24 \pm 10.47$ \\
\hline
\end{tabular}

It is evident from the table 2 that significant difference was found between the means of all the lung function parameters of cotton mill workers and hospital staff. 
Table-2: Comparison of lung functions between study and control group.

\begin{tabular}{|c|c|c|c|c|c|}
\hline Tests & Readings & $\begin{array}{c}\text { Mill Worker } \\
(\mathbf{n = 1 5 0})\end{array}$ & $\begin{array}{c}\text { Hospital workers } \\
(\mathbf{n = 1 5 0})\end{array}$ & T-value & $\begin{array}{c}\text { Level of Significance } \\
(\mathbf{P} \text { value })\end{array}$ \\
\hline \multirow{2}{*}{ FEV $_{1}$} & Actual & $2.12 \pm 0.60$ & $2.55 \pm 0.42$ & -7.094 & .000 \\
& \% Predicted & $73.85 \pm 17.53$ & $86.80 \pm 10.20$ & -7.815 & .000 \\
\hline \multirow{2}{*}{ FVC } & Actual & $2.36 \pm 0.66$ & $3.00 \pm 0.46$ & -9.613 & .000 \\
\cline { 2 - 5 } & \% Predicted & $66.91 \pm 15.14$ & $84.67 \pm 9.44$ & -12.190 & .000 \\
\hline \multirow{2}{*}{ FEV1/ } & Actual & $89.38 \pm 9.38$ & $84.36 \pm 6.96$ & 5.269 & .000 \\
\cline { 2 - 5 } FVC & $\%$ predicted & $109.45 \pm 11.84$ & $102.77 \pm 9.08$ & 5.478 & .000 \\
\hline PEFR & Actual & $359.20 \pm 114.84$ & $397.08 \pm 83.05$ & -3.273 & .001 \\
\cline { 2 - 5 } & $\%$ predicted & $79.53 \pm 22.76$ & $93.04 \pm 46.49$ & -3.198 & .002 \\
\hline
\end{tabular}

All the tests other than PEFR proved to be statistically significant, showing poorer values for cotton mill workers as compared to hospital workers.

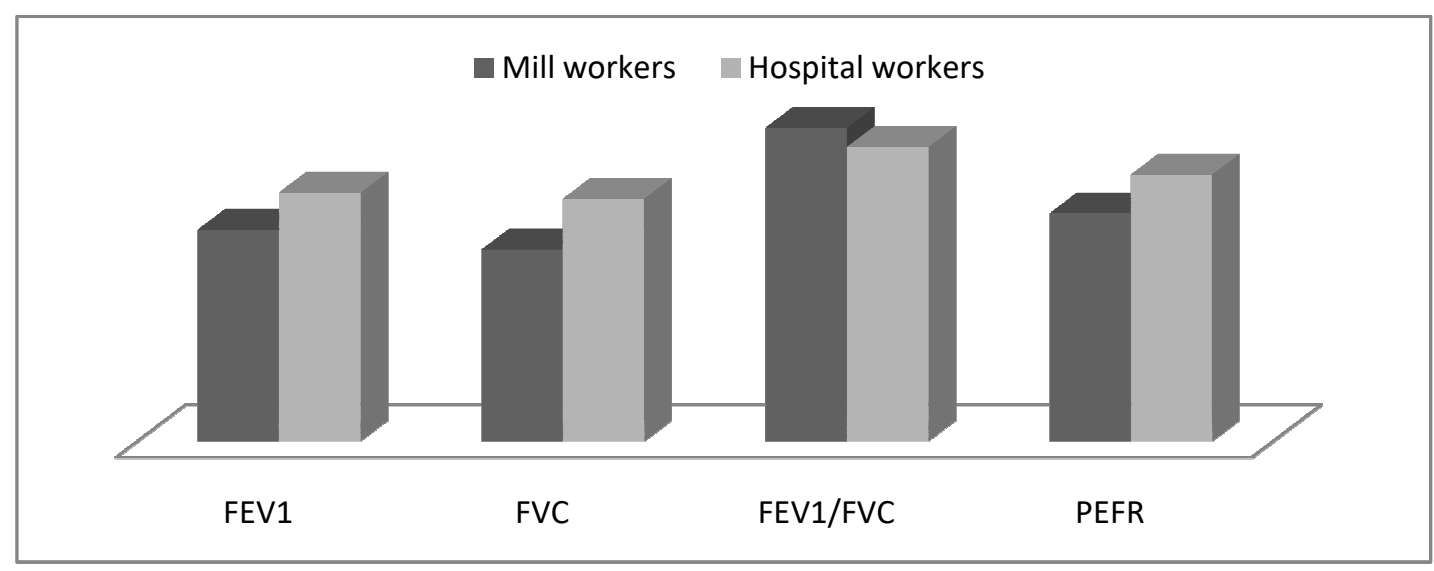

Fig-1: Comparison of ventilatory parameters between two groups

Table No-3: Effect of duration of exposure to Cotton dust.

\begin{tabular}{|c|c|c|c|}
\hline \multirow{2}{*}{ Tests } & Readings & Pierson (r) value & Level Of Significance \\
\hline \multirow{2}{*}{ FEV $_{1}$} & Actual & -0.607 & .000 \\
\cline { 2 - 3 } & \%Predicted & -0.376 & .000 \\
\hline \multirow{2}{*}{ FVC } & Actual & -0.548 & .000 \\
\cline { 2 - 3 } & \%Predicted & -0.402 & .000 \\
\hline \multirow{2}{*}{ FEV1/ FVC } & Actual & -0.176 & .031 \\
\cline { 2 - 4 } & \%predicted & -0.078 & .344 \\
\hline \multirow{2}{*}{ PEFR } & Actual & -0.398 & .000 \\
\cline { 2 - 4 } & \%predicted & -0.258 & .001 \\
\hline
\end{tabular}

Descriptive Statistics related to Mill workers. Independent variable: duration of exposure.

Table 3 reveals that the significant negative correlation was found in cotton mill workers between duration of exposure to the cotton dust and the pulmonary functions. The parameters like FEV1 and FVC were significantly reduced with increase in duration of exposure, while FEV1/FVC and PEFR were also reduced but the change was not statistically significant.

Even though the mill workers showed greater deficits in all the tests the results between mill workers and hospital workers were not statistically significant for FEV1 and PEFR whereas for other tests the results were significant. 


\section{Discussion}

In our study, the lung functions were found to be significantly lower in cotton mill workers as compared to control group even though the percentage predicted values were reported to be lesser in control group as well. Unlike ours the lung functions were not much disturbed in previous studies which may be because we could collect data during the working shift and it is well known fact that in Byssinosis the respiratory symptoms are severe during the working hours as compared to off duty hours $[10,11,12]$. This could also be due to the fact that we involved CMWs only from the sections where cotton dust is known to be more. The other factors like inefficient dust control measures, unavailability of preventive measures like nasal masks, not able to change the current occupation because of unavailability of jobs, poor economical conditions etc might also be responsible for these poor lung functions. Our study group had all males but the previous studies conducted in Bombay textile mill and in south India on women workers showing the similar results [13,14]. The researchers from Pakistan also reported the high prevalence rate at Karachi where the similarity in working conditions has been noted as like India [15]. The lower pulmonary function values in controls might be because of air pollution in Mumbai which was also reported by previous studies conducted in urban population $[10,11,16]$.

In our study actual values of FEV1 and FVC declined with the duration of exposure in cotton mill workers. These findings were matching with the other studies conducted in India by Sangeeta Vyas (Jaipur) and Tiwari et al (Wardha) who noted higher respiratory morbidities in CMWs as compared to apparently healthy population $[17,18]$.

As like our findings many researchers also have noted the negative correlation of lung functions along with increased duration of exposure [19,20,21]. Certain researchers like Roger K Larson et al, in their study of cotton gin workers in San Joaquin Valley has failed to find any detrimental effect of cotton exposure on the rate of decline of pulmonary functions which could be due to awareness of occupational health in European countries [22].

\section{Conclusion}

It can be concluded that even after the modernization of the cities like Mumbai, the severity of byssinosis has not reduced but aggravated, compromising the pulmonary functions of cotton mill workers and showing the negative correlation with duration of exposure to cotton dust.

Acknowledgements: We are thankful to the department of chest medicine, Mahatma Gandhi memorial ESIS hospital, Parel Mumbai for providing the required instrument and also medical ethics committee, Topiwala national medical college, and By.L. Nair Hospital, Mumbai Central, Mumbai for granting us a permission to conduct the study.

Funding: Nil, Conflict of interest: None initiated, Permission from IRB: Yes

\section{References}

1. M. N. Gupta. Review of byssinosis in India, Ind. J. Med. Res. Sept 1969: 9, 57.

2. Cotes J. E. Lung Functions, third edition, Oxford blackwell scientific publishers. 1975, page 2-4, 24-30, 99-108.

3.Proceedings of fifth Asian conference of occupational health. Nov. 17-20, 1968, Bombay, page 102-12.

4. Douglas K. H. Lee. Environmental factors in respiratory disease. Academic press New York and London, 1972, page 253-57.

5. American thoracic society guidelines for lung function testing. Selection of reference values and interpretative strategies. Am. Rev. Resp. Dis. 1991; 144, 1201-18.

6. Miller MR, Hankinson J, Brusasco V, Burgos F, et al. Standardization of spirometry. Eur Respir J. 2005 Aug;26(2):319-38.

7. Jain SK, Ramaiah $\mathrm{T}$ J. Normal standards of pulmonary function tests of healthy Indian men of 15 to 40 years age comparison of different regression equations (predicted formulae). Ind.J.Med.Res.1969;57.

8. Kamat SR, Sarma BS, Raju VR, Venkataraman C et al. Indian norms for pulmonary functions, observed values, prediction equations and inter correlation. $\mathrm{Jr}$ Asso Phys Ind 1977 Aug ; 25(8):531-40. 
9. Udwadia FE, Sunawala VM, Shetye VM. Lung function studies in healthy subjects. Jr Asso Phys Ind 1987 36(7):491-96.

10. Kamat SR, Kamat GR, Salpekar VY, Lobo E. Distinguishing Byssinosis from COPD. Am. Rev. Resp. Dis. July $1981 ; 124$ : 31-40.

11. Schilling RSF. Byssinosis in cotton and other textile workers, Lancet 1956 Aug ;18(2), 261-64,391-25.

12. Hinson AV, Schlunssen V, Agodokpessi G, Siqsqaards T, Fayomi B. The prevalence of byssinosis among cotton mill workers in the north of Benin. Int $\mathbf{J}$ Occup Environ Med. 2014 Oct;5(4):194-200.

13. Murlidhar V, Murlidhar VJ, Kanhere V. Byssinosis in Bombay textile mill. Natl Med J India 1995 Sep-Oct; 8(5):204-7.

14. J.V. Jannet, G. P. Jayanthi. Pulmonary health status of ginning factory women labourers in Tirupur, India. Indian Journal of Occupational and Environmental medicine December 2006; Vol 10 (3): 116-120.

15. Farooque MI, Khan B, Aziz E, Moosa M, Raheel M, Kumar S, Mansuri FA. Byssinosis: as seen in cotton spinning mill workers of Karachi. J Pak Med Assoc 2008 Feb; 58(2): 95-98.

16. Krishna MT, Salvi SS. What is the association between air pollution and allergic diseases? JAPI. 2002; 50: 221-225.
17. Sangeeta Vyas. A study of pulmonary function tests in workers of different dust industries. International journal of basic and applied medical sciences 2012 May-Aug;Vol.2 (2) 15-21. Available on: hhtp://www. cibtech.org/jms.htm

18. Tiwari RR, Pathak MC and Zodpey SP. Respiratory morbidities in cotton textile workers. Lung India 1999; XVII (1): 23-25.

19. Mansouri F, Pili JP, Abbasi A, Soltani M, Izadi N. Respiratory problems among cotton mill workers. Lung india 2016; Mar-Apr;33(2):163-66.

20. Hasan Kaharaman, Mustafa Haki Sucakli, Talat Kilic, Mustafa Celik, nurahan Koksal and Hasan Cetin Ekerbicer. Longitudinal pulmonary functional loss in cotton textile workers: A 5-year follow-up study. Med Sci Monit. 2013; 19: 1176-1182.

21. Sunita Kalasuramath, Malay Kumar, Surendra Mannan K, D V Deshpande, Vinodkumar C S. Incidance of byssinosis, effects of indoor pollutants and associated risk factors on lung functions among women working in cotton mills. Int J Basic and Appl Physiol 2015; 4(1): 152-60.

22. Roger K. Larson, Martin L. Barman. Longitudinal study of pulmonary function in cotton Gin workers in the San Joaquin Valley. Chest October 1989; Vol 96 (4): 819-823.

\section{How to cite this article?}

Ingle A.S, Venkatraman B, Bagale K, Choudhary R.Comparative study of Ventilatory Functions of Cotton Mill Workers, Mumbai, India. Int J Med Res Rev 2016;4(10):1833-1837.doi:10.17511/ijmrr. 2016.110.20. 